\title{
Case Report \\ Q Fever with Unusual Exposure History: A Classic Presentation of a Commonly Misdiagnosed Disease
}

\author{
Randall J. Nett, ${ }^{1,2}$ Earl Book, ${ }^{3}$ and Alicia D. Anderson ${ }^{4}$ \\ ${ }^{1}$ Career Epidemiology Field Officer Program, Centers for Disease Control and Prevention (CDC), Atlanta, GA 30333, USA \\ ${ }^{2}$ Communicable Disease Control and Prevention Bureau, Montana Department of Public Health and Human Services, \\ Helena, MT 59610, USA \\ ${ }^{3}$ St. Peter's Medical Group, Helena, MT 59601, USA \\ ${ }^{4}$ Rickettsial Zoonoses Branch, CDC, Atlanta, GA 30333, USA
}

Correspondence should be addressed to Randall J. Nett, gge5@cdc.gov

Received 15 March 2012; Accepted 6 June 2012

Academic Editors: R. Colodner, M. de Gorgolas, and S. Yazar

Copyright (C) 2012 Randall J. Nett et al. This is an open access article distributed under the Creative Commons Attribution License, which permits unrestricted use, distribution, and reproduction in any medium, provided the original work is properly cited.

We describe the case of a man presumptively diagnosed and treated for Rocky Mountain spotted fever following exposure to multiple ticks while riding horses. The laboratory testing of acute and convalescent serum specimens led to laboratory confirmation of acute Q fever as the etiology. This case represents a potential tickborne transmission of Coxiella burnetii and highlights the importance of considering $\mathrm{Q}$ fever as a possible diagnosis following tick exposures.

\section{Introduction}

Coxiella burnetii is an enzootic and endemic bacterial pathogen in the United States and causative agent of Q fever [1]. Cattle, sheep, and goats are the most common animal reservoirs, and $C$. burnetii is shed in the birth products of infected animals $[1,2]$. While humans typically become infected through inhalation of contaminated aerosols and dust, possible tickborne transmission of $C$. burnetii has been reported [2].

The incubation period of Q fever is usually 2-3 weeks [2]. Approximately half of persons infected with C. burnetii will remain asymptomatic. The most common clinical manifestation of acute $\mathrm{Q}$ fever is a nonspecific and febrile flu-like illness [2]; thus, the diagnosis is challenging and few patients receive appropriate treatment. Acute $Q$ fever is treated with doxycycline and is most successful when initiated within three days of symptom onset. Approximately $1-5 \%$ of acutely ill patients will develop chronic Q fever, most commonly manifesting as endocarditis in those with valvular heart disease or immune compromising conditions [3].

Rickettsia rickettsii is an arthropod-borne bacterium and part of the spotted fever group rickettsiae (SFGR). The SFGR are transmitted through the bites of infected ixodid ticks
[4]. R. rickettsii infection causes Rocky Mountain spotted fever (RMSF). RMSF generally occurs 2-14 days following infection and is characterized by fever, rash, headache, and abdominal pain [5]. Approximately 20\% of patients do not develop a rash or have an atypical rash [6]. Prompt treatment with doxycycline increases the likelihood for recovery.

\section{Case Presentation}

A 57-year-old male presented on June 29, 2011 with a fiveday history of fever, headache, nausea, rash, and fatigue. The patient had no history of immunosuppression. He reported exposure to multiple ticks and mosquitoes while riding horses in South Dakota in early June 2011. On examination, the patient was afebrile, diaphoretic, and had left upper quadrant tenderness. Except for documented tinea versicolor on his trunk, no other rashes were present. The remainder of the physical examination was unremarkable. Laboratory results from serum collected at the time of presentation showed a mild leukopenia, acute renal failure, elevated liver transaminases, and elevated anti-SFGR immunoglobulin (Ig)G; initial testing for Q fever was negative (Table 1). The patient was treated with doxycycline for 14 days for the presumptive diagnosis of RMSF and subsequently recovered. 
TABLE 1: Case-patient laboratory test results, Montana, 2011.

\begin{tabular}{|c|c|}
\hline Laboratory test & Result \\
\hline White blood cell count (g/L) & 4.1 \\
\hline Platelet count $(\mathrm{g} / \mathrm{L})$ & 115 \\
\hline Blood urea nitrogen $(\mathrm{mg} / \mathrm{dL})$ & 23 \\
\hline Creatinine (mg/dL) & 1.7 \\
\hline Aspartate aminotransferase (IU/L) & 132 \\
\hline Alanine aminotransferase (IU/L) & 193 \\
\hline Alkaline phosphatase (IU/L) & 106 \\
\hline \multicolumn{2}{|c|}{ Coxiella burnetii antibody titers ${ }^{\dagger}$ by specimen } \\
\hline \multicolumn{2}{|c|}{ Acute $^{\ddagger}$} \\
\hline IgG*/IgM phase I & $<1: 16 /$ not done \\
\hline IgG/IgM phase II & $<1: 16 /<1: 16$ \\
\hline \multicolumn{2}{|l|}{ Convalescent ${ }^{\S}$} \\
\hline IgG/IgM phase I & $\geq 1: 256 / 1: 64$ \\
\hline IgG/IgM phase II & $\geq 1: 256 / \geq 1: 256$ \\
\hline \multicolumn{2}{|l|}{ SFGR antibody titers ${ }^{\dagger}$ by specimen } \\
\hline \multicolumn{2}{|l|}{ Acute $^{\ddagger}$} \\
\hline $\operatorname{IgG}$ & $1: 64$ \\
\hline $\operatorname{Ig} M$ & $<1: 64$ \\
\hline \multicolumn{2}{|l|}{ Convalescent ${ }^{\S}$} \\
\hline $\operatorname{IgG}$ & $1: 128$ \\
\hline $\operatorname{Ig} M$ & $<1: 64$ \\
\hline \multicolumn{2}{|c|}{$\begin{array}{l}\text { Borrelia burgdorferi antibody" (IgG and/or } \\
\text { IgM) by specimen }\end{array}$} \\
\hline Acute $^{\ddagger}$ & Negative \\
\hline Convalescent ${ }^{\S}$ & Negative \\
\hline \multicolumn{2}{|l|}{ West Nile virus antibody" } \\
\hline $\operatorname{IgG}$ & Negative \\
\hline $\operatorname{IgM}$ & Negative \\
\hline \multicolumn{2}{|c|}{$\begin{array}{l}\text { * IgG: immunoglobulin G; IgM: immunoglobulin M; SFGR: spotted fever } \\
\text { group rickettsiae. } \\
{ }^{\dagger} \text { Testing performed using indirect immunofluorescence assay. } \\
\text { ‡Acute specimen collected on June } 29,2011 \text {. } \\
{ }^{\text {}} \text { Convalescent specimen collected on July } 12,2011 \text {. } \\
\text { "Testing performed using enzyme-linked immunosorbent assay (ELISA); } \\
\text { therefore, no titers reported. }\end{array}$} \\
\hline
\end{tabular}

However, convalescent testing on July 12 revealed that the patient experienced no subsequent increase in anti-SFGR antibody, while a significant increase in phase I and II antiC. burnetii IgG occurred (Table 1). The patient was judged unlikely to have been a case of RMSF as there was no demonstrable anti-SFGR IgM and no change in IgG titers. However, the patient was laboratory confirmed as infected with $C$. burnetii as demonstrated by a four-fold rise in phase II IgG-specific antibody titer between acute and convalescent specimens.

\section{Discussion}

The patient's symptom onset began approximately 2-3 weeks after exposure to multiple ticks suggesting possible tickborne disease transmission. The most common mode of human transmission is inhalational, but cases of tickborne transmission have been described [7, 8]. Over 40 tick species are naturally infected with $C$. burnetii and tick transmission to various mammals has been documented [2]. Although the patient did not report livestock contact, it is not possible to exclude this route of transmission in a natural setting because the organism can become windborne and carried for long distances [9]. Ticks from the patient or from the area of exposure were not available for testing so it is not possible to prove that $C$. burnetii infection occurred because of a tick bite rather than exposure to contaminated aerosols and dust.

The patient's initial diagnosis of RMSF was based on an elevated SFGR IgG antibody in the acute specimen. This was a reasonable assumption as the patient had a history of tick exposure, a compatible clinical presentation for RMSF and met the CDC surveillance case definition for a laboratory supportive SFGR case. However, the patient's SFGR IgG antibody did not show a significant rise in titer in the convalescent sample and no IgM antibody was detected. An acute serum specimen taken during the first week of illness is often negative as a rise in antibody titer does not typically occur until at least 7 days after symptom onset. For these reasons, it is more likely that the patient's titer to SFGR was caused by a previously undiagnosed infection rather than an acute infection as SFGR IgG response can be elevated for extended periods following acute infection [10].

This case of $\mathrm{Q}$ fever suggests a potential tickborne transmission of C. burnetii and highlights the importance of evaluating patients with suspected tickborne disease for $\mathrm{Q}$ fever in areas known to be endemic for C. burnetii [8]. Considering the diagnosis of $\mathrm{Q}$ fever is especially important for patients who are pregnant, immunocompromised, or have valvular heart disease as prompt antibiotic treatment can prevent life-threatening complications.

\section{Conflict of Interests}

The authors report no conflict of interests.

\section{Consent}

The patient provided written informed consent for this case report.

\section{Disclaimer}

The findings and conclusions of this report are those of the authors and do not necessarily represent the views of the Centers for Disease Control and Prevention or the institutions with which the authors are affiliated.

\section{Acknowledgments}

The authors thank the Lewis and Clark City-County Health Department for their assistance in this investigation, Dr. Steven Helgerson for paper review, and Drs. Jennifer McQuiston and Robert Massung for discussions and helpful advice. 


\section{References}

[1] J. H. Mcquiston, R. C. Holman, C. L. McCall, J. E. Childs, D. L. Swerdlow, and H. A. Thompson, "National surveillance and the epidemiology of human Q fever in the United States, 19782004," The American Journal of Tropical Medicine and Hygiene, vol. 75, no. 1, pp. 36-40, 2006.

[2] M. Maurin and D. Raoult, "Q fever," Clinical Microbiology Reviews, vol. 12, no. 4, pp. 518-553, 1999.

[3] S. J. Cutler, M. Bouzid, and R. R. Cutler, "Q fever," Journal of Infection, vol. 54, no. 4, pp. 313-318, 2007.

[4] A. F. Azad and C. B. Beard, "Rickettsial pathogens and their arthropod vectors," Emerging Infectious Diseases, vol. 4, no. 2, pp. 179-186, 1998.

[5] L. F. Chen and D. J. Sexton, "What's new in Rocky Mountain spotted fever?" Infectious Disease Clinics of North America, vol. 22, no. 3, pp. 415-432, 2008.

[6] A. S. Chapman, J. S. Bakken, S. M. Folk et al., "Diagnosis and management of tickborne rickettsial diseases: Rocky Mountain spotted fever, ehrlichioses, and anaplasmosis-United States: a practical guide for physicians and other health-care and public health professionals," MMWR Recommendations and Reports, vol. 55, no. 4, pp. 1-27, 2006.

[7] C. M. Ecklund, R. R. Parker, and D. B. Lackman, "A case of Q fever probably contracted by exposure to ticks in nature," Public Health Reports, vol. 62, no. 39, pp. 1413-1416, 1947.

[8] J. M. Rolain, F. Gouriet, P. Brouqui et al., "Concomitant or consecutive infection with Coxiella burnetii and tickborne diseases," Clinical Infectious Diseases, vol. 40, no. 1, pp. 82-88, 2005.

[9] H. Tissot-Dupont, M. A. Amadei, M. Nezri, and D. Raoult, "Wind in November, Q fever in December," Emerging Infectious Diseases, vol. 10, no. 7, pp. 1264-1269, 2004.

[10] M. L. Clements, J. S. Dumler, P. Fiset et al., "Serodiagnosis of Rocky Mountain spotted fever: comparison of IgM and IgG enzyme-linked immunosorbent assays and indirect fluorescent antibody test," Journal of Infectious Diseases, vol. 148, no. 5, pp. 876-880, 1983. 


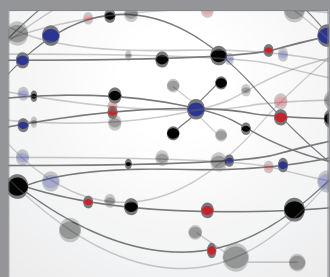

The Scientific World Journal
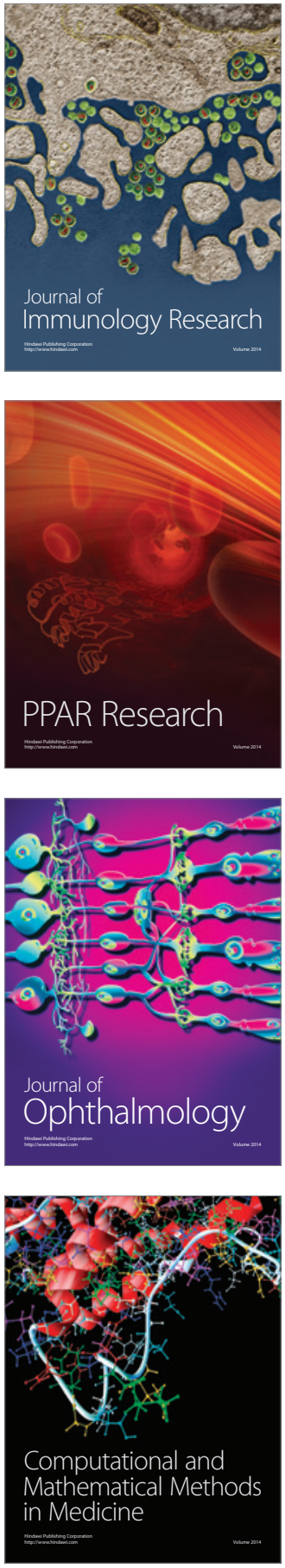

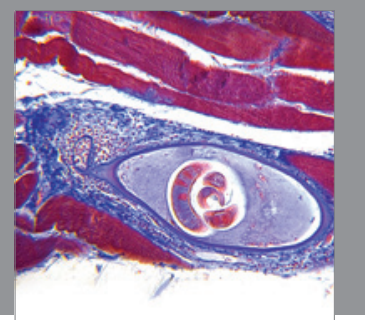

Gastroenterology

Research and Practice
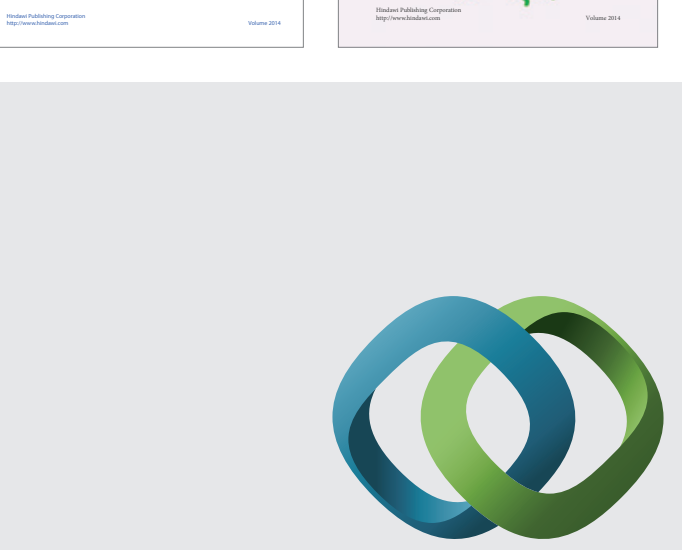

\section{Hindawi}

Submit your manuscripts at

http://www.hindawi.com
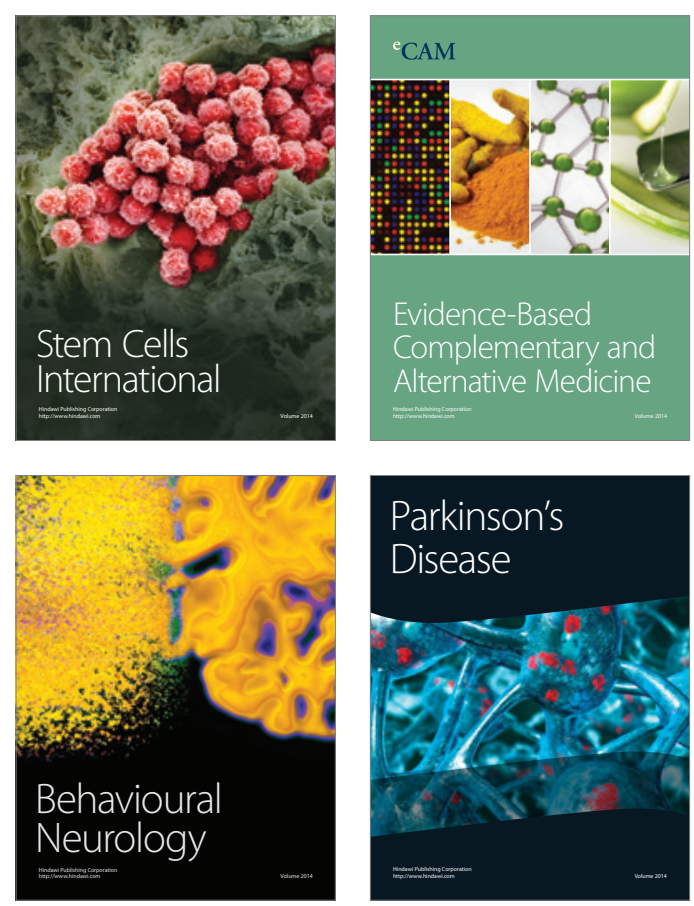

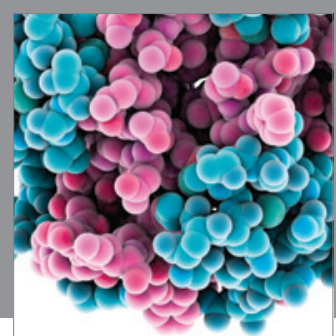

Journal of
Diabetes Research

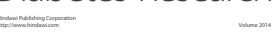

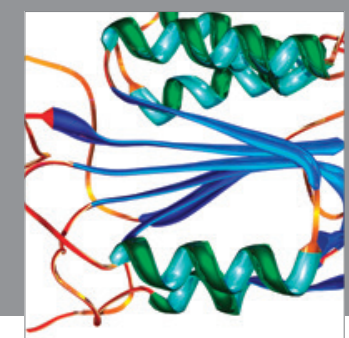

Disease Markers
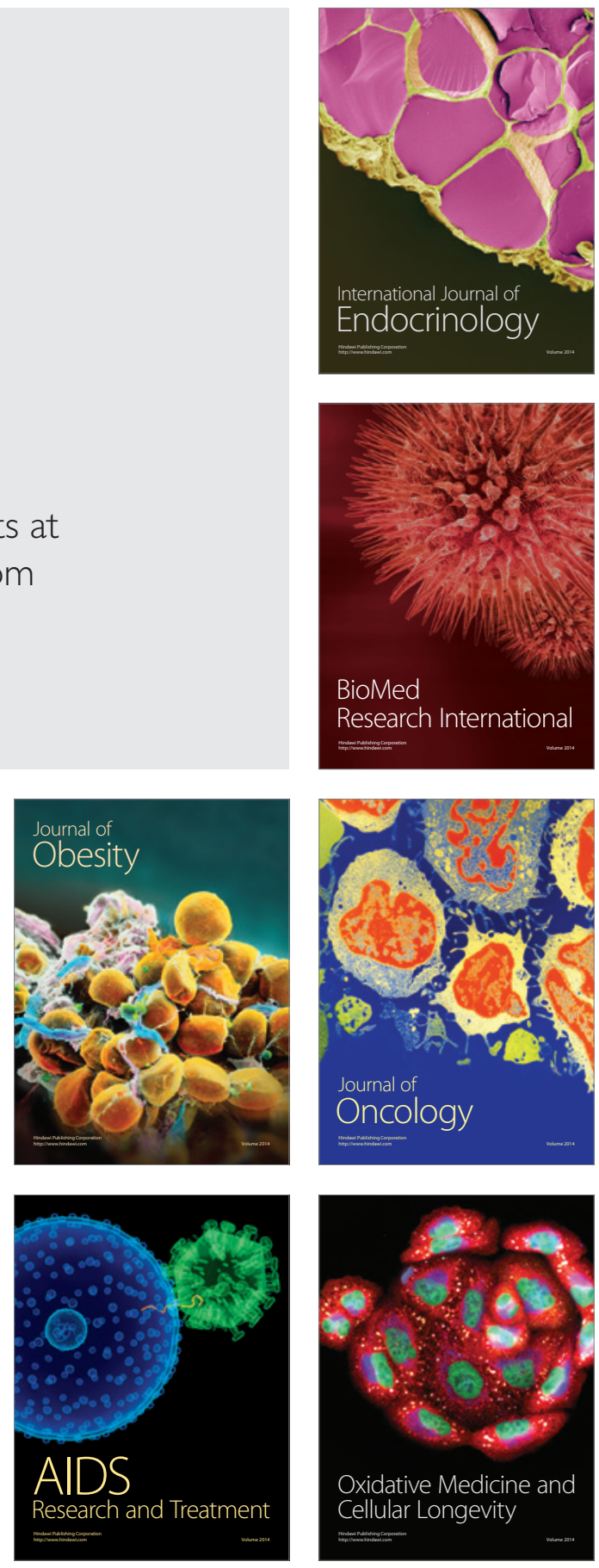